Fixed Point Theory, 20(2019), No. 1, 3-18

DOI: $10.24193 /$ fpt-ro.2019.1.01

http://www.math.ubbcluj.ro/ nodeacj/sfptcj.html

\title{
RELATION-THEORETIC METRICAL FIXED POINT THEOREMS UNDER NONLINEAR CONTRACTIONS
}

\author{
MD AHMADULLAH, MOHAMMAD IMDAD AND RQEEB GUBRAN \\ Department of Mathematics, Aligarh Muslim University \\ Aligarh-202002, U.P., India \\ E-mail: ahmadullah2201@gmail.com; mhimdad@gmail.com; rqeeeb@gmail.com
}

\begin{abstract}
We establish fixed point theorems for nonlinear contractions on a metric space (not essentially complete) endowed with an arbitrary binary relation. Our results extend, generalize, modify and unify several known results especially those contained in Samet and Turinici [Commun. Math. Anal. 13, 82-97 (2012)] and Alam and Imdad [J. Fixed Point Theory Appl. 17(4), 693-702 (2015)]. Interestingly a corollary to one of our main results proved under symmetric closure of any binary relation remains a sharpened version of a theorem due to Samet and Turinici. Finally, we use examples to highlight the realized improvements in the results proved in this paper.

Key Words and Phrases: Complete metric spaces, binary relations, contraction mappings, fixed point.
\end{abstract}

2010 Mathematics Subject Classification: 47H10, 54H25.

Acknowledgements. All the authors are grateful to anonymous referee for his valuable suggestions and comments. Also, the first author is thankful to University Grant Commission, New Delhi, Govt. of India, for awarding Moulana Azad National Fellowship.

\section{REFERENCES}

[1] M. Ahmadullah, J. Ali, M. Imdad, Unified relation-theoretic metrical fixed point theorems under an implicit contractive condition with an application, Fixed Point Theory Appl., 42(2016), 1-15.

[2] A. Alam, M. Imdad, Nonlinear contractions in metric spaces under locally T-transitive binary relations, Fixed Point Theory 19 (2018), no. 1, 13-24.

[3] A. Alam, M. Imdad, Relation-theoretic contraction principle, J. Fixed Point Theory Appl., 17(2015), no. 4, 693-702.

[4] A. Alam, M. Imdad, Relation-theoretic metrical coincidence theorems, Filomat, 31(2017), 44214439.

[5] M. Altman, An integral test for series and generalized contractions, Amer. Math. Mon., 82(1975), 827-829.

[6] S. Banach, Sur les opérations dans les ensembles abstraits et leur application aux équations intégrales, Fund. Math., 3(1922), 133-181.

[7] H. Ben-El-Mechaiekh, The Ran-Reurings fixed point theorem without partial order: A simple proof, J. Fixed Point Theory Appl., 16(2015), 373-383.

[8] S.K. Chatterjea, Fixed point theorems, C.R. Acad. Bulg. Sci., 25(1972), 727-730. 
MD AHMADULLAH, MOHAMMAD IMDAD AND RQEEB GUBRAN

[9] L.B. Ćirić, A generalization of Banach's contraction principle, Proc. Amer. Math. Soc., 45(1974), 267-273.

[10] S. Ghods, M.E. Gordji, M. Ghods, M. Hadian, Comment on "Coupled fixed point theorems for nonlinear contractions in partially ordered metric spaces" [Lakshmikantham and Ćirić, Nonlinear Anal. TMA 70 (2009) 4341-4349], J. Comput. Anal., 14(2012), no. 5, 958-966.

[11] J. Jachymski, The contraction principle for mappings on a metric space with a graph, Proc. Amer. Math. Soc., 136(2008), no. 4, 1359-1373.

[12] R. Kannan, Some results on fixed points II, Am. Math. Mon., 76(1969), 405-408.

[13] B. Kolman, R.C. Busby, S. Ross, Discrete Mathematical Structures, Third Edition, PHI Pvt. Ltd., New Delhi, 2000.

[14] S. Lipschutz, Schaum's Outlines of Theory and Problems of Set Theory and Related Topics, McGraw-Hill, New York, 1964.

[15] R.D. Maddux, Relation Algebras, Studies in Logic and the Foundations of Mathematics, 150, Elsevier B. V., Amsterdam, 2006.

[16] J.J. Nieto, R. Rodríguez-López, Contractive mapping theorems in partially ordered sets and applications to ordinary differential equations, Order, 22(2005), no. 3, 223-239.

[17] A.C.M. Ran, M.C.B. Reurings, A fixed point theorem in partially ordered sets and some applications to matrix equations, Proc. Amer. Math. Soc., 132(2004), no. 5, 1435-1443.

[18] B. Samet, M. Turinici, Fixed point theorems on a metric space endowed with an arbitrary binary relation and applications, Commun. Math. Anal., 13(2012), 82-97.

[19] M. Turinici, Abstract comparison principles and multivariable Gronwall-Bellman inequalities, J. Math. Anal. Appl., 117(1986), no. 1, 100-127.

[20] M. Turinici, Fixed points for monotone iteratively local contractions, Demonstratio Math., 19(1986), no. 1, 171-180.

[21] M. Turinici, Linear contractions in product ordered metric spaces, Ann. Univ. Ferrara, 59(2013), 187-198.

[22] M. Turinici, Ran-Reurings fixed point results in ordered metric spaces, Libertas Math., 31(2011), 49-55.

[23] M. Turinici, Nieto-Lopez theorems in ordered metric spaces, Math. Student, 81(2012), no. 1-4, 219-229.

Received: May 11, 2016; Accepted: September 1st, 2016. 
